\section{First-line therapeutic options for advanced non-small-cell lung cancer in the molecular medicine era}

\author{
Enrica Capelletto', Silvia Novello*,1 \& Giorgio V Scagliotti ${ }^{1}$
}

\begin{abstract}
Lung cancer is the leading cause of cancer-related mortality worldwide in both sexes, expected to account, in the near future, for more than $30 \%$ of all cancer-related deaths. Recently, improvements in the systemic therapy of non-small-cell lung cancer according to histology and tumor molecular characteristics led to a progressive prolongation of survival, more clinically meaningful in selected groups of patients with tumors harboring specific genomic alterations. As the search for individualized therapeutic approaches could represent one of the potential ways to improve survival expectancy of non-small-cell lung cancer patients with advanced disease stage, the aim of this review is to discuss how currently to select the best front-line therapeutic strategy.
\end{abstract}

Lung cancer is the leading cause of cancer-related mortality worldwide in both sexes and accounts for 26 and $29 \%$ of all female and male cancer deaths, respectively [1]. Incidence rates in women started declining in the late 1990s, more than a decade after observing the same trend in men [2]. Probably, differences in lung cancer incidence patterns between men and women reflect historical differences in tobacco use.

The overall 5-year survival rate for lung cancer is currently approximately $16 \%$ and this rate drops down to $4 \%$ for those patients diagnosed at advanced stages $[1,3]$.

Owing to relevant epidemiological changes and recent advances regarding systemic therapy of non-small-cell lung cancer (NSCLC) according to histology and molecular characteristics, this review summarizes how to currently choose the best strategy of treatment in front-line setting for patients presenting with advanced disease stage.

\section{Role of cytotoxic chemotherapy}

A meta-analysis spanning 25 years of clinical research established that platinum-based chemotherapy doublets are the backbone of treatment for advanced NSCLC. This approach guarantees a modest but statistically significant improvement in survival and quality of life $[4,5]$. In addition, there is evidence that cisplatin is more effective than carboplatin in terms of objective response rate (ORR; 30 vs $24 \%$, respectively; $\mathrm{p}<0.001$ ), despite a less favorable toxicity profile [6].

Commonly used platinum doublets demonstrate comparable activity with differential toxicity profiles (Table 1) [7-9]. In one study, the combination of cisplatin plus docetaxel showed a higher ORR and a better overall survival (OS) in comparison with the other explored regimens [9].

A retrospective review and meta-analysis demonstrated that triplet combinations are associated with an increase in ORR but not in progression-free (PFS) and OS compared with doublets [10]. Overall these findings suggest that chemotherapy for all comers as front-line approach for advanced NSCLC had already reached a therapeutic plateau.

'Department of Oncology, University of Turin, San Luigi Hospital, Regione Gonzole 10, 10043 Orbassano (Torino), Italy

*Author for correspondence: Tel.: +39 011 9026978; Fax: +39 011 9038616; silvia.novello@unito.it

\section{KEYWORDS}

- biomarkers

- chemotherapy • histology

- non-small-cell lung cancer

- targeted therapies 


\begin{tabular}{|c|c|c|c|c|c|c|}
\hline Study & Regimen & Patients (n) & ORR (\%) & $\begin{array}{l}\text { Median OS } \\
(95 \% \mathrm{Cl}) \text {; months }\end{array}$ & $\begin{array}{l}\text { 1-year survival } \\
(95 \% \mathrm{Cl}) ; \%\end{array}$ & Ref. \\
\hline ECOG & Cis/pacli 135 mg/m² & 288 & 21 & $7.8(7.0-8.9)$ & $31(26-36)$ & [7] \\
\hline \multirow[t]{3}{*}{1594} & Cis/gem & 288 & 22 & $8.1(7.2-9.4)$ & $36(31-42)$ & \\
\hline & Cis/doce & 289 & 17 & $7.4(6.6-8.8)$ & $31(26-36)$ & \\
\hline & Carbo/pacli 225 mg/m² & 290 & 17 & $8.1(7.0-9.5)$ & $34(29-40)$ & \\
\hline \multirow[t]{3}{*}{ ILCP } & Cis/vnr & 201 & 30 & $9.5(8.3-11.0)$ & 37 (NR) & {$[8]$} \\
\hline & Cis/gem & 205 & 30 & $9.8(8.6-11.2)$ & 37 (NR) & \\
\hline & Carbo/pacli 225 mg/m² & 201 & 32 & $10.0(9.0-12.5)$ & 43 (NR) & \\
\hline \multirow[t]{3}{*}{ TAX 326} & Cis/vnr & 404 & 25 & $10.1(9.0-11.3)$ & $41(35-46)$ & [9] \\
\hline & Cis/doce & 408 & 32 & $11.3(10.1-12.4)$ & $46(42-51)$ & \\
\hline & Carbo/doce & 406 & 24 & $9.4(8.7-10.6)$ & $38(33-43)$ & \\
\hline
\end{tabular}

Histology-driven chemotherapy

Evidence generated from a better knowledge of tumor cell biology and the development of drugs targeting specific enzymatic pathways of the tumor cell, such as the folate pathway, have shown that histology may become one of relevant finding in the therapeutic decision-making process of NSCLC.

In a large Phase III randomized trial, cisplatin plus pemetrexed was not inferior to cisplatin plus gemcitabine for all the tested clinical efficacy outcomes [11]. This study included a preplanned analysis for histology, and patients with nonsquamous NSCLC benefited more from the pemetrexed-based regimen in terms of OS (hazard ratio [HR]: $0.81 ; 95 \% \mathrm{CI}$ : 0.7-0.94; $\mathrm{p}=0.005)$, while PFS did not differ between the two groups. On the contrary, patients with squamous cell carcinoma showed a marginally significant superiority in OS (10.8 vs 9.4 months, respectively; HR: 1.23 ; 95\% CI: $1.00-1.51 ; \mathrm{p}=0.05$ ) and PFS (5.5 vs 4.4 months, respectively; HR: 1.36 ; $95 \% \mathrm{CI}: 1.12-1.65$; $\mathrm{p}<0.05$ ) for patients treated with cisplatin plus gemcitabine. Cisplatin plus pemetrexed resulted in a statistically significant inferior incidence of grade 3 and 4 neutropenia, anemia, thrombocytopenia, febrile neutropenia and alopecia $(\mathrm{p} \leq 0.001)$, whereas drug-related grade 3 and 4 nausea was higher $(\mathrm{p}=0.004)$.

The differential activity of pemetrexed in nonsquamous histology has been also supported by a retrospective analysis of a Phase III trial of single-agent pemetrexed versus docetaxel in the second-line treatment of recurrent NSCLC [12] and, prospectively, in a Phase III maintenance study of single-agent pemetrexed [13]. The benefit of continuation maintenance pemetrexed in nonsquamous NSCLC has been further supported by another Phase III study for advanced nonsquamous NSCLC [14,15].

These results have been related to a different expression of thymidylate synthase (TS), one of the main enzymes of the folate pathway targeted by pemetrexed, in different histologic subtypes of NSCLC, which may justify the lower efficacy of pemetrexed in the squamous histology being TS higher in this histotype [16].

Based on these data, patients with adenocarcinoma are more likely to benefit from a pemetrexed-based regimen, and in 2008, pemetrexed in combination with cisplatin was been granted as first-line treatment for patients with advanced NSCLC other than predominantly squamous cell histology.

The predictive role of histology is a peculiar finding in most of the studies investigating pemetrexed in NSCLC, while in previous studies, histology was not associated with any prognostic or predictive value $[7,8,17]$.

\section{Role of biological agents}

- Monoclonal antibodies anti-VEGF: bevacizumab

Clinical research efforts with targeted agents have endeavored to improve survival beyond that provided by cytotoxic chemotherapy. The randomized trial ECOG E4599 assessed the addition of bevacizumab, a monoclonal antibody targeting the VEGF and inhibiting its interaction with the VEGF receptors, to carboplatin plus paclitaxel in patients with metastatic nonsquamous NSCLC. The study showed a statistically significant improvement in median OS 
for the group of bevacizumab-treated patients [18]. Median PFS and ORR were also improved. Adenocarcinoma histology was associated with a greater OS benefit (14.2 vs 10.3 months, respectively). The administration of bevacizumab was well tolerated, even if an excess of severe bleeding episodes was reported in the bevacizumab arm (4.4 vs $0.7 \%$, respectively; $\mathrm{p}<0.001$ ).

Based on the outcome of this trial, in 2006, the US FDA rapidly granted approval for bevacizumab administered in combination with carboplatin plus paclitaxel for the initial treatment of patients with unresectable, locally advanced, recurrent or metastatic, nonsquamous NSCLC [19].

In another front line Phase III study, bevacizumab was assessed in combination with cisplatin plus gemcitabine [20]. The study explored bevacizumab at two different dose levels, 7.5 and $15 \mathrm{mg} / \mathrm{kg}$, showing a statistically significant improvement in PFS, the primary end point of the study, in both bevacizumab arms when compared with chemotherapy alone. The ORR was also significantly greater in both bevacizumab arms (37.8 and 30.6\%, respectively, vs $21.6 \%)$. All treatment groups achieved a median OS greater than 13 months, but no difference in median OS was observed among treatment groups [21].

A systematic review and meta-analysis of four trials assessing the efficacy of chemotherapy plus bevacizumab versus chemotherapy alone in NSCLC included 2200 patients and confirmed a significantly higher ORR and a better PFS for bevacizumab treated patients with both 7.5 and $15 \mathrm{mg} / \mathrm{kg}$, while there was no statistically significant increase in OS [22]. The discrepancy between a clear benefit in PFS and a not consistent benefit in OS in the above mentioned studies may be the consequence of a different impact of postprogression therapies.

In the USA, bevacizumab is currently licensed at dose of $15 \mathrm{mg} / \mathrm{kg}$ in combination with carboplatin plus paclitaxel as first-line therapy in patients with advanced nonsquamous NSCLC, while in Europe its use is in combination with platinum-based chemotherapy at the dose of both 7.5 or $15 \mathrm{mg} / \mathrm{kg}$.

SaiL was a large Phase IV trial undertaken in a real-world population in order to assess the safety and efficacy of first-line bevacizumab combined with several standard chemotherapy regimens [23]. The study confirmed the manageable and consistent safety profile of bevacizumab, as well as its efficacy on treatment outcomes. Safety data coming from different studies excluded an excess of the risk of bleeding following bevacizumab use in NSCLC patients with CNS metastases $[24,25]$ and led to the approval by EMA of bevacizumab in combination with a platinum-based chemotherapy even in patients with untreated CNS metastases [26].

A multicenter Phase II study evaluated the safety and efficacy of bevacizumab and pemetrexed maintenance after initial therapy with pemetrexed and carboplatin plus bevacizumab [27]. The study showed an ORR of 55\% (95\% CI: 41-69\%) with a favorable toxicity profile. The median PFS and OS were 7.8 and 14.1 months, respectively. These promising results led to a subsequent Phase III comparison against the standard regimen containing bevacizumab. The PointBreak study was a multicenter, randomized Phase III study of pemetrexed/carboplatin plus bevacizumab as induction treatment followed by maintenance pemetrexed and bevacizumab compared with paclitaxel/carboplatin plus bevacizumab followed by bevacizumab maintenance in patients with advanced nonsquamous NSCLC [28]. The primary end point of superior OS for the pemetrexed containing arm was not met (12.6 vs 13.4 months; HR: $1.00 ; \mathrm{p}=0.949$ ); however, the study showed a modest improvement in PFS for the pemetrexed arm (6.0 vs 5.6 months; HR: 0.83; $\mathrm{p}=0.012$ ) and a good safety profile [29].

Another study (AVAPERL1) investigated the efficacy of bevacizumab versus bevacizumab plus pemetrexed as maintenance treatment in nonsquamous patients who achieved disease control following induction with cisplatin and pemetrexed plus bevacizumab. The median PFS was significantly improved with the doublet (10.2 vs 6.6 months; HR: $0.50 ; \mathrm{p}<0.001)$ but this benefit was associated with significant increase of grade 3 and 4 toxicities in the combination maintenance arm [30].

\section{- Reversible \& irreversible EGF receptor-tyrosine kinase inhibitors}

Activation of the EGF receptor (EGFR) pathway promotes tumor growth and progression, stimulates cancer cell proliferation, invasion and metastasis, and inhibits apoptosis [31]. Although the therapeutic inhibition of this pathway have been pursued for more than 20 years only recently, following the detection of EGFR-sensitizing mutation in the EGFR gene tyrosine kinase domain, 
this pathway re-emerged as an attractive target for novel targeted strategies for NSCLC.

Table 2 summarizes the initial series of Phase III trials evaluating the efficacy of oral EGFR-tyrosine kinase inhibitors (TKIs; gefitinib and erlotinib) in combination with platinum-based chemotherapy in the first-line setting [32-35]. None of these studies demonstrated any statistically significant difference in OS between arms. Despite negative results, all these trials detected efficacy of the EGFR-TKIs associated with clinical characteristics as never smoking status, Asian ethnicity, female sex and adenocarcinoma histology [36,37].

The clinical development of gefitinib faced several hurdles. Although in 2003, single-agent gefitinib received accelerated approval by the FDA on the basis of encouraging Phase II data, the conditional approval was subsequently restricted in 2004 because of the negative results of the Phase III ISEL trial [38].

INTEREST was a large Phase III study that compared second-line gefitinib to docetaxel in unselected patients with adenocarcinoma of the lung and it demonstrated the noninferiority of gefitinib in comparison with docetaxel (HR: 1.02; 95\% CI: 0.90-1.15). Patients treated with gefitinib had a lower rate of treatment-related toxicity ( 8.5 vs $40.7 \%$ ) and a better improvement in quality of life and, once more, this study confirmed the superior activity of gefitinib in specific subgroups of patients with NSCLC [39].

In 2004, somatic gene mutations of the EGFR gene were discovered and their presence related to the higher response to EGFR-TKIs [40-42]. The most common mutations are in frame deletion in exon 19 around codons $746-750$ (45-50\% of all somatic EGFR mutations) and a missense mutation at codon 858 (L858R) in exon 21 (35-45\% of all EGFR mutations). The frequency of mutations is ethnicity-related and more frequent in never smokers, women and patients with adenocarcinoma [43]. This discovery led to a new wave of studies that explored the role of gefitinib and other EGFR-TKIs in clinically enriched or molecularly defined patient populations (Table 3).

First, IPASS provided evidence of efficacy of an EGFR-TKI inhibitor as front-line treatment in a clinically enriched population [44]. The study, designed to demonstrate the noninferiority of gefitinib versus chemotherapy in terms of PFS, met its primary end point and also showed the superiority of gefitinib versus chemotherapy in terms of PFS in the intentionto-treat analysis (HR: 0.74; 95\% CI: 0.65-0.85; $\mathrm{p}<0.0001)$. Patients with tumor samples available for molecular analysis were considered in a subgroup analysis, which showed the superiority of gefitinib in terms of PFS in patients with EGFR-mutated tumors (HR: 0.48; 95\% CI: 0.36-0.64; p < 0.0001). On the contrary, chemotherapy was significantly better in EGFR wild-type patients (HR: 2.85; 95\% CI: 2.05-3.98; p < 0.0001) [44]. Final OS data, based on $78 \%$ of events, showed no differences between gefitinib and chemotherapy in the whole population (18.6 vs 17.3 months, respectively, HR: 0.91 ; 95\% CI: 0.76-1.10; $\mathrm{p}=0.11$ ) and in the mutation positive subgroup (HR: 1.00: 95\% CI: 0.76-1.33). The improvement in PFS in gefitinib treated patients was coupled with a significant improvement in quality of

\begin{tabular}{|c|c|c|c|c|c|c|}
\hline Study & TKI & Treatment & ORR (\%) & $\begin{array}{l}\text { Median PFS } \\
\text { (months) }\end{array}$ & Median OS (months) & Ref. \\
\hline INTACT 1 & Gefitinib & $\begin{array}{l}\text { Cis/gem + gefitinib } 500 \text { mg/day vs } \\
\text { cis/gem + gefitinib } 250 \text { mg/day vs cis/gem } \\
\text { + placebo }\end{array}$ & $\begin{array}{l}50.3 \text { vs } 51.2 \text { vs } 47.2 \\
(p=N S)\end{array}$ & $\begin{array}{l}5.5 \text { vs } 5.8 \text { vs } 6.0 \\
(p=0.7633)\end{array}$ & $\begin{array}{l}9.9 \text { vs } 9.9 \text { vs } 10.9 \\
(p=0.4560)\end{array}$ & [32] \\
\hline INTACT 2 & Gefitinib & $\begin{array}{l}\text { Carbo/pacli + gefitinib } 500 \text { mg/day vs } \\
\text { carbo/pacli + gefitinib } 250 \mathrm{mg} / \text { day vs } \\
\text { carbo/pacli + placebo }\end{array}$ & $\begin{array}{l}30.0 \text { vs } 30.4 \text { vs } 28.7 \\
(p=N S)\end{array}$ & $\begin{array}{l}4.6 \text { vs } 5.3 \text { vs } 5.0 \\
(p=0.0562)\end{array}$ & 8.7 vs 9.8 v $9.9(p=0.64)$ & [33] \\
\hline TALENT & Erlotinib & $\begin{array}{l}\text { Cis/gem + erlotinib } 150 \mathrm{mg} / \text { day vs } \\
\text { cis/gem + placebo }\end{array}$ & $\begin{array}{l}31.5 \text { vs } 29.9 \\
(p=N S)\end{array}$ & $\begin{array}{l}5.53 \text { vs } 5.74 \\
\text { (HR: } 0.98 ; 95 \% \mathrm{Cl}: \\
0.86-81.11 ; \mathrm{p}=0.74)\end{array}$ & $\begin{array}{l}10.0 \text { vs } 10.2 \text { (HR: } 1.06 \\
95 \% \mathrm{Cl}: 0.90-91.23 \\
\mathrm{p}=0.49)\end{array}$ & [34] \\
\hline TRIBUTE & Erlotinib & $\begin{array}{l}\text { Carbo/pacli + erlotinib } 150 \mathrm{mg} / \text { day vs } \\
\text { carbo/pacli + placebo }\end{array}$ & $\begin{array}{l}21.5 \text { vs } 19.3 \\
(p=0.36)\end{array}$ & $\begin{array}{l}5.1 \text { vs } 4.9(H R: 0.93 \\
p=0.36)\end{array}$ & $\begin{array}{l}10.6 \text { vs } 10.5(\mathrm{HR}: 0.99 ; 95 \% \\
\mathrm{Cl}: 0.86-81.16 ; \mathrm{p}=0.95)\end{array}$ & [35] \\
\hline
\end{tabular}

Carbo: Carboplatin; Cis: Cisplatin; Gem: Gemcitabine; HR: Hazard ratio; NS: Not significant; ORR: Objective response rate; OS: Overall survival; Pacli: Paclitaxel; PFS: Progression-free survival; TKl: Tyrosine kinase inhibitor. 


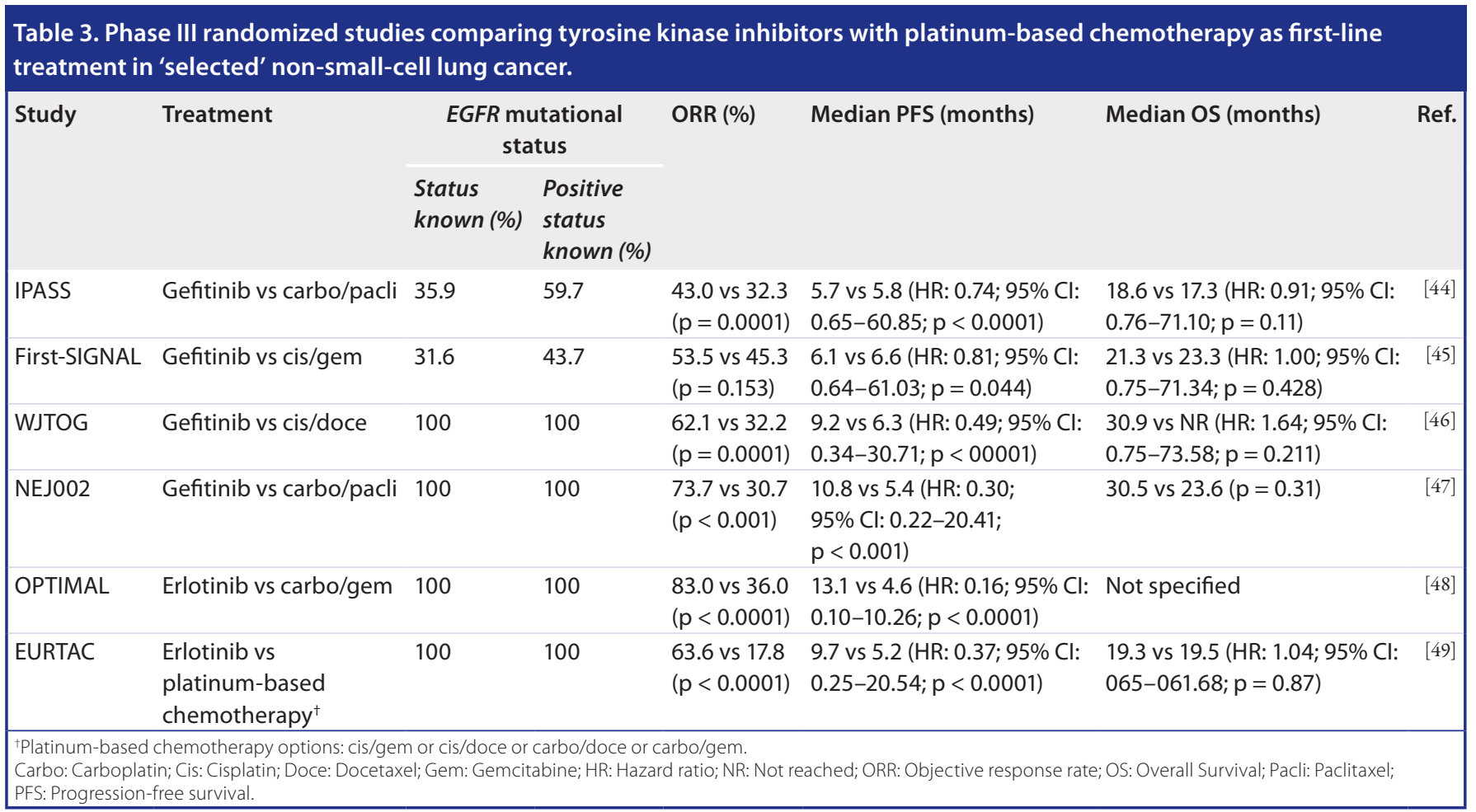

life and a lower incidence of grade 3-4 adverse events compared with chemotherapy [50].

A similar study, the First-SIGNAL trial, compared gefitinib versus cisplatin plus gemcitabine in Korean patients [45]. While OS and PFS were similar in both groups (Table 3), the shape of the PFS curves resembled that seen in IPASS. Again in the EGFR mutation-positive patients, median PFS was significantly improved in the gefitinib arm (8.4 vs 6.7 months) as well as ORR (84.6 vs $37.5 \%$; $=0.002)$.

A series of other Phase III studies were conducted in genotype-defined EGFR mutant population which compared single-agent EGFR-TKI with cytotoxic chemotherapy and all invariably showed the superiority in terms of ORR and PFS of single-agent EGFR-TKI (Table 3) [46-49].

In July 2009, gefitinib received from EMA the approval for the treatment of locally advanced or metastatic NSCLC with activating mutations of the EGFR gene across all lines of therapy and, currently, is the treatment of choice for patients with advanced NSCLC harboring EGFR mutations.

Among the above mentioned studies, mostly conducted among Asiatic patients, the EURTAC trial was the first performed in a Caucasian population and it proved the superiority of erlotinib versus chemotherapy as front-line treatment [49]. Median PFS was 9.7 months (95\% CI: 8.4-12.3) for patients treated with erlotinib compared with 5.2 months (95\% CI: 4.5-5.8) for those treated with standard chemotherapy.

Sequential use of chemotherapy and EGFR TKIs has been tested as an alternative strategy in the first-line setting. FAST-ACT was a Phase II study that investigated whether the sequential administration of erlotinib and chemotherapy versus chemotherapy alone improves clinical outcomes in unselected, previously untreated patients with advanced NSCLC [51]. Patients were randomly assigned to receive erlotinib or placebo on days $15-28$ of a 4 -week cycle that included cisplatin or carboplatin plus gemcitabine. The primary end point of the study was non-progression rate (NPR) at 8 weeks. No significant difference in NPR was observed between the two treatment arms ( 80.3 vs $76.9 \%$, in the erlotinib and placebo arm respectively; $\mathrm{p}=0.51$ ). ORR was higher in the chemotherapy-erlotinib $\operatorname{arm}$ (35.5 vs $24.4 \%$, respectively) and median PFS was also significantly longer in the erlotinib arm (29.4 vs 23.4 weeks, in the erlotinib and placebo arm respectively; HR: 0.47; 95\% CI: $0.33-0.68 ; \mathrm{p}=0.0002)$ No significant difference in OS was observed [51]. These encouraging results led to a large confirmatory randomized Phase III trial, the FAST-ACT II trial, which showed a significantly prolonged PFS with erlotinib versus placebo (7.6 vs 6.0 months, 
respectively; HR: 0.57 ; 95\% CI: $0.46-0.70$; $\mathrm{p}<0.0001)$. ORR was significantly improved in the erlotinib arm (42.9 vs $17.8 \%$, respectively; $\mathrm{p}<0.0001)$ and a nonsignificant trend toward longer OS was seen with erlotinib versus placebo (18.3 vs 14.9 months, respectively; HR: 0.78; 95\% CI: $0.60-1.02 ; \mathrm{p}=0.069)$ [52].

Another interesting therapeutic challenge for physicians is how best to manage at the best patients who benefited from EGFR-TKIs, but then experienced disease progression after a durable response. Several cases report and retrospective analyses indicated that responsive patients to EGFR-TKIs were successfully under therapeutic control after subsequent re-administration of the same EGFR-TKIs or another agent with a similar mechanism of action, supporting the hypothesis that these $E G F R$-mutated tumors continue to be 'oncogene-addicted' to EGFR [53-55]. Prospective trials have recently showed that the re-administration of EFGR-TKIs in those patients who initially responded to these agents and then were treated at progression with systemic chemotherapy could be a valid therapeutic option at the time of second progression albeit with a lower ORR and PFS [56,57].

Acquired resistance to EGFR-TKIs is most commonly characterized by the presence of the gatekeeper mutation T790M [58,59]. Among second-generation TKIs afatinib (BIBW2992) is an irreversible ErbB-family blocker with potent activity against NSCLCs harboring activating EGFR mutations and/or the gatekeeper mutation T790M, albeit at lower potency. It has been recently evaluated in several clinical trials for advanced NSCLC with promising results (Table 4) [60-63]. The LUX-Lung 3 was a front-line Phase III trial of afatinib versus cisplatin/pemetrexed for patients with advanced lung adenocarcinoma harboring EGFR-activating mutations. Patients treated with afatinib had a median PFS, the primary end point of the study, of 11.1 versus 6.9 months for the chemotherapy group (HR: $0.58 ; 95 \%$ CI: $0.43-0.78 ; \mathrm{p}=0.0004$ ). ORR was also significantly higher with afatinib ( 56 vs $23 \%$; p < 0.001), reporting a consistent delay in time to deterioration of cancer-related symptoms [62]. Most common afatinib-related adverse events were diarrhea (95\%), skin rash (62\%) and paronychia (57\%). On the basis of results coming from the LUX-Lung 3 trial, afatinib has been recently approved by the FDA and by EMA for the first-line treatment of EGFR mutation-positive metastatic NSCLC.
Another study, LUX-Lung 6 compared afatinib with cisplatin plus gemcitabine in Asiatic patients with EGFR mutation-positive advanced adenocarcinoma of the lung (Table 4). The study showed a clear benefit in terms of median PFS (11.0 vs 5.6 months; HR: 0.28; 95\% CI: $0.20-0.39 ; \mathrm{p}<0.0001)$ and ORR ( 66.9 vs $23.0 \%$; $p<0.0001)$ in favor of afatinib, which showed a favorable tolerability profile, with few cases of grade 3 and 4 toxicities [63]. Currently, afatinib is currently under evaluation in a Phase II trial against gefitinib as first-line treatment in advanced NSCLC patients with EGFR-activating mutations [64].

Another second-generation TKI, dacomitinib (PF-00299804) - an irreversible inhibitor of EGFR/HER1, HER2 and HER4, has been evaluated in a Phase II trial versus erlotinib in previously treated (one/two prior chemotherapy regimens were allowed) advanced NSCLC patients. The median PFS was 2.86 months for patients treated with dacomitinib and 1.91 months for those treated with erlotinib (HR: 0.66; 95\% CI: $0.47-0.91 ; p=0.012$ ), while median OS was 9.53 and 7.44 months, respectively (HR: 0.80; 95\% CI: 0.56-1.13; $\mathrm{p}=0.205)$. The most common treatment-related adverse events were dermatologic and gastrointestinal disorders, mostly of grade 1 and 2, and more frequently associated with dacomitinib [65]. These results represented the backbone information for an ongoing Phase III study in which 800 patients will be enrolled having as primary end point PFS [66].

\section{- Monoclonal antibodies anti-EGFR: cetuximab}

Cetuximab is a chimeric monoclonal antibody that selectively binds the extracellular domain of the EGFR on the tumor cell and inhibits the receptor-associated tyrosine kinase activation $[67,68]$. A large Phase III trial (FLEX) compared cisplatin plus vinorelbine with the same combination plus cetuximab in chemotherapy-naive advanced NSCLC patients with EGFR-positive tumors ( $\geq 1 \%$ positive cells) as assessed by immunohistochemistry [69]. The addition of cetuximab demonstrated a small but statistically significant benefit in terms of median OS over chemotherapy alone (11.3 vs 10.1 months, respectively, HR $0.87 ; p=0.0441$ ), while PFS was similar in both arms. The main cetuximab-associated toxicity was acne-like rush, which occurred in $10 \%$ of patients. Similar results were observed in another trial with a different chemotherapy backbone 
Table 4. Relevant clinical trials of afatinib for advanced non-small-cell lung cancer.

\begin{tabular}{|c|c|c|c|c|c|c|c|}
\hline Study & Phase & Treatment & Selection criteria & ORR (\%) & Median PFS (months) & $\begin{array}{l}\text { Median OS } \\
\text { (months) }\end{array}$ & Ref. \\
\hline LUX-Lung 1 & $\mathrm{Ilb} / \mathrm{III}$ & $\begin{array}{l}\text { Afatinib vs } \\
\text { placebo }\end{array}$ & $\begin{array}{l}\text { Stage IIIB/IV adenocarcinoma } \\
\text { patients after failure of gefitinib } \\
\text { and/or erlotinib and previous } \\
\text { one/two chemotherapy }\end{array}$ & $\begin{array}{l}7.0 \text { vs }<1.0 \\
(p=0.0071)\end{array}$ & $\begin{array}{l}3.3 \text { vs } 1.1 \text { (HR: } 0.38 \\
95 \% \text { Cl: } 0.31-30.48 \\
p<0.0001)\end{array}$ & $\begin{array}{l}10.8 \text { vs } 12.0 \\
\text { (HR: } 1.08 ; 95 \% \mathrm{Cl}: \\
0.86-81.35 \\
\mathrm{p}=0.74)\end{array}$ & {$[60]$} \\
\hline LUX-Lung 2 & II & Afatinib & $\begin{array}{l}\text { Stage IIIB/IV EGFR mutation- } \\
\text { positive adenocarcinoma } \\
\text { patients after failure of one } \\
\text { previous chemotherapy or } \\
\text { chemotherapy-naive }\end{array}$ & 61 & 10.1 (95\% Cl: 8.12-13.80) & $\begin{array}{l}24.8(95 \% \mathrm{Cl}: \\
21.98-38.74)\end{array}$ & {$[61]$} \\
\hline LUX-Lung 3 & III & $\begin{array}{l}\text { Afatinib vs } \\
\text { cisplatin/ } \\
\text { pemetrexed }\end{array}$ & $\begin{array}{l}\text { Stage IIIB/IV EGFR mutation- } \\
\text { positive/chemotherapy-naive } \\
\text { adenocarcinoma patients }\end{array}$ & $\begin{array}{l}56.0 \text { vs } 23.0 \\
(p<0.0001)\end{array}$ & $\begin{array}{l}11.1 \text { vs } 6.9(\mathrm{HR}: 0.58 ; 95 \% \mathrm{Cl} \text { : } \\
0.43-40.78 ; p=0.0004)\end{array}$ & NR & [62] \\
\hline
\end{tabular}

[70]. This second study did not show improvement of PFS, but showed a trend to improved OS, the secondary end point of the study, for patients treated with cetuximab plus chemotherapy ( 9.7 vs 8.4 months, respectively, HR: 0.890; 95\% CI: 0.75-1.05; $\mathrm{p}=0.17)$.

A meta-analysis considered four cetuximab studies and included 1003 and 1015 patients treated with chemotherapy plus cetuximab or chemotherapy alone, respectively [71]; it showed a $9 \%$ reduction in the risk of disease progression (HR: 0.91; 95\% CI: 0.83-1.00; $\mathrm{p}=0.06$ ), a $13 \%$ reduction in the risk of death (HR: 0.87; 95\% CI: $0.78-0.96 ; \mathrm{p}=0.005)$ and an approximately $50 \%$ increase in ORR (odds ratio: 1.48 ; 95\% CI: $1.22-1.80$; $<<0.0001$ ) for cetuximab-treated patients [71].

High levels of EGFR expression correlate with in vitro sensitivity to cetuximab $[72,73]$. Recently, FLEX data were reanalyzed and the immunohistochemistry assessment of EGFR intensity and frequency in tumor cells was used to generate, on a continuous scale of $0-300$, an EGFR immunohistochemistry (EGFR IHC) score for each assessable patient, in order to investigate whether tumor EGFR expression levels were associated with a predictive role. Treatment outcomes were analyzed in patients with a low $(<200)$ and high $(\geq 200)$ EGFR IHC score, representing 69 and $31 \%$ of evaluable patients, respectively [74]. For patients with a high EGFR IHC score, median OS was longer in the chemotherapy plus cetuximab arm than in the control arm (12.0 vs 9.6 months, respectively; HR: 0.73, 95\% CI:
$0.58-0.93 ; \mathrm{p}=0.011)$, without significant increase in cetuximab related side effects. No corresponding survival benefit was observed in the group of patients with low EGFR IHC score (median OS of 9.8 vs 10.3 months, respectively; HR: 0.99; 95\% CI: 0.84-1.16; $\mathrm{p}=0.88$ ) [74].

A fully humanized monoclonal antibody targeting the EGFR extracellular domain III, necitumumab, is currently under investigation having the potential benefit of lower hypersensitivity reaction risk as compared with cetuximab and also equivalent antibody-dependent cell-mediated cytotoxicity [75]. The Phase III trial INSPIRE (NCT00982111) that evaluated the addition of necitumumab to cisplatin/pemetrexed as first-line treatment for advanced nonsquamous NSCLC was prematurely closed owing to the increased risk of thromboembolic events in the experimental arm [76]. The SQUIRE trial (NCT00981058) is another Phase III study of first-line cisplatin/gemcitabine plus necitumumab versus chemotherapy alone for advanced squamous NSCLC [77]. The study fully accrued the requested number of patients and a recent press release indicated that it met its primary end point.

\section{- ALK inhibitors}

ALK is one of the newest and attractive biological targets in NSCLC. ALK is aberrantly activated because of a chromosomal rearrangement in approximately $4 \%$ of NSCLC tumors, leading to the expression of an oncogenic fusion protein, such as EML4-ALK $[78,79]$. In NSCLC, the $A L K$ gene rearrangement is associated with 
specific clinical-pathological features, including male sex, young age, absent or minimal smoking history, adenocarcinoma histology and usually mutual exclusivity between EML4-ALK and EGFR and KRAS mutations [80-82]. Preclinical and clinical studies have shown that cancer cells harboring EML4-ALK and other ALK abnormalities are exquisitely sensitive to ALK inhibition [79,83].

The identification of EML4-ALK as an oncogenic driver in NSCLC occurred relatively early in the clinical development of crizotinib, an ALK inhibitor originally under investigation as a c-MET inhibitor, and led to the rapid clinical development of this drug [84]. Initial results from the Phase I study clearly indicated significant and clinically relevant tumor shrinkage in the majority of enrolled patients [85]. Subsequently, an expansion cohort of 82 NSCLC patients harboring the ALK rearrangement was enrolled at the recommended dose of $250 \mathrm{mg}$ twice daily. The ORR for the expanded cohort was $57 \%$ (46 partial responses and one complete response). An additional $33 \%$ of patients had stable disease at the 8-week assessment [86]. An update of this study with 119 enrolled patients was subsequently presented showing a consistent ORR of $61 \%$ with two complete responses and 69 partial responses and the median PFS for was 10 months (95\% CI: 8.00-15.00) [87]. Based upon the encouraging ORR of the Phase I study, a large multicenter second- and subsequent-line study in ALK-positive NSCLC patients was initiated. Patient characteristics largely corresponded to those of the previous study and the ORR was $51 \%$ [88]. In both the Phase I and II trials, the majority of responses was achieved during the first 8 weeks of treatment and duration of response was 48.1 and 41.9 weeks, respectively [87,88].

In August 2011, based on the Phase I and II trial data, the FDA granted in USA accelerated approval of crizotinib for the first or subsequent lines of treatment of locally advanced or metastatic ALK-positive NSCLC [89]. Final FDA approval will be contingent on analysis of outcome measures in the ongoing Phase III studies $[90,91]$.

PROFILE 1007, a Phase III study evaluating the use of crizotinib versus pemetrexed or docetaxel as second line of treatment for ALKpositive NSCLC patients met its primary end point by demonstrating the superiority of crizotinib over chemotherapy in prolonging PFS (7.7 vs 3.0 months, respectively; HR: 0.49 ) and
ORR (65 vs $20 \%$; $\mathrm{p}<0.0001$ ), while the safety profile was acceptable [92]. These findings led to the EMA authorization for the use of crizotinib as the standard of care for previously treated ALK-positive NSCLC patients in Europe.

As already reported above, the TS level may predict the sensitivity to pemetrexed-based chemotherapy in different histologic subtypes of NSCLC, being inversely correlated with pemetrexed efficacy [16]. A recent study evaluating the role of pemetrexed-based chemotherapy in ALK-positive NSCLC patients, showed lower TS levels than the median values established in unselected cases. A low TS level has been observed in almost $83 \%$ of the evaluated patients $(\mathrm{p}=0.039)$ and the few ALK-positive NSCLC patients with high TS levels had the poorest survival outcomes observed [93]. These findings suggest that differences in TS expression levels in ALK-positive NSCLC patients may predict the differential responses to pemetrexed, but also justify the superior efficacy of pemetrexed compared with docetaxel in this subset of patients, as observed in the PROFILE 1007.

Another Phase III trial PROFILE 1014 (NCT01154140) is currently actively recruiting patients to evaluate the efficacy and safety of crizotinib versus cisplatin or carboplatin/pemetrexed as a first-line treatment for previously untreated ALK-positive nonslquamous NSCLC patients [91]. The primary end point of the study is PFS, while ORR and OS are included among the secondary end points. A superiority Phase III trial testing the same crizotinib schedule has been designed for the east Asian population [94].

Crizotinib has recently also demonstrated a marked anti-tumor activity in patients with advanced NSCLC harboring ROSI chromosomal rearrangements, which leads to the expression of oncogenic ROS1 fusion kinases and to sensitivity to ROS kinase inhibition, without any overlap with other oncogenic drivers. This rearrangement has been detected in almost $1 \%$ of NSCLC cases, usually in younger patients, never or light smokers and with adenocarcinoma histology [95,96].

The expansion cohort of the Phase I study of crizotinib PROFILE 1001 (NCT00585195) recruited patients with advanced NSCLC harboring ROS1 rearrangement, as determined using a break-apart FISH assay [97]. The study showed an ORR of $54 \%$ and a disease control rate at 8 weeks of $85 \%$, with a safety profile similar to that observed in ALK-positive NSCLC patients receiving crizotinib [97]. 
Conclusion \& future perspective

Moving toward the next decade and looking to the several landmark changes in the understanding the biology and treatment of NSCLC that we observed in the last few years, it is almost impossible to deny that significant improvements have been made in extending survival of selected groups of patients with tumors harboring specific genomic alterations. Although such genetic changes have been detected in more than $50 \%$ of adenocarcinoma and, more recently also, in the vast majority of squamous cell carcinoma and small cell lung cancers, effective and approved targeted therapy approaches are currently available only for a significant minority of our patients. EGFR-TKIs should be the preferred front-line treatment choice for advanced patients with nonsquamous tumors harboring EGFR-sensitizing

\section{EXECUTIVE SUMMARY}

\section{Background}

- Lung cancer is the leading cause of cancer-related mortality worldwide, and the actual challenge is to better personalize the therapeutic approaches to improve survival expectancy.

\section{Role of standard chemotherapy}

- Platinum-based chemotherapy doublets are the backbone of treatment for non-small-cell lung cancer (NSCLC), giving a modest but significant improvement in survival and quality of life in comparison with best supportive care.

- Cisplatin is more effective than carboplatin in terms of objective response rate (ORR) and overall survival (OS).

- Triplet combinations are associated with increased ORR but similar survival.

\section{Histology-driven chemotherapy}

- On the basis of survival benefit, pemetrexed in combination with cisplatin has been granted as first-line treatment for advanced nonsquamous NSCLC.

\section{Role of biological agents}

- Bevacizumab, a monoclonal antibody anti-VEGFR, has been licensed in the USA in combination with carboplatin/paclitaxel as first-line treatment option for advanced nonsquamous NSCLC, on the basis of its survival benefit; in Europe it is licensed in combination with any platinum-based chemotherapy.

- In NSCLC patients with EGFR mutation-positive tumors, first-line single-agent therapy with either gefitinib or erlotinib, two reversible EGFR-TKIs, when compared with standard platinum-based chemotherapy, are associated with a significantly longer PFS, higher ORR, a more favorable toxicity profile and better quality of life.

- Gefitinib and erlotinib received from EMA, the authorization for the treatment of locally advanced or metastatic EGFR mutation-positive NSCLC, across all lines of therapy.

- Afatinib, an irreversible EGFR-TKI, has recently showed a clear survival benefit in terms of PFS in NSCLC patients harboring EGFR-activating mutations, receiving from the US FDA and the EMA the authorization for first-line treatment in this subgroup of patients.

- Cetuximab, a monoclonal antibody anti-EGFR, in association with platinum-based chemotherapy has demonstrated a small but significant survival benefit in terms of OS, despite a more severe toxicity profile.

- Crizotinib, an ALK inhibitor, has showed significant and clinically relevant tumor shrinkage in the majority of ALK-positive NSCLC patients.

- In the USA, it has been licensed for the treatment of locally advanced or metastatic ALK-positive NSCLCs across all lines of therapy, while in Europe its use is allowed in previously treated NSCLC patients harboring ALK gene rearrangements.

- Crizotinib has recently demonstrated a marked anti-tumor activity in NSCLC patients harboring ROS1 chromosomal rearrangements.

\section{Conclusion \& future perspective}

- The definition of homogeneous subgroups of tumors with the same genetic characteristics and the search for individualized approaches could improve survival expectancy for NSCLC patients. 
mutations. For patients harboring $A L K$ gene rearrangements an attractive and promising strategy of treatment is represented by crizotinib and second-generation ALK-inhibiting agents. Up to date, despite the huge effort of clinical research therapeutic choices based on histology are still the standard of care for the majority of patients with advanced NSCLC. In the setting of nononcogene addicted nonsquamous NSCLC patients, either the combination of a platinum agent with pemetrexed or the addition of bevacizumab to carboplatin and paclitaxel are doable therapeutic solutions and the choice should be guided by clinical, pathologic and cost-efficacy issues. In squamous histology, doublet platinum-based chemotherapy remains the standard approach.

Although the implementation of the systematic sequencing of the lung cancer genome will definitively lead to a progressive increase of the proportion of patients that will be treated by specific targeted therapies, it is quite unlikely that a druggable target or more than one target will be discovered and efficiently blocked in every tumor. More potential crosstalks exist between cancer pathways, allowing new DNA mutations to create new pathways to cancer when pre-existing ones are blocked. Given the seemingly almost intrinsic genetic instability of many late-stage cancers we should question if we will be able to truly cure most victims of widespread metastatic cancer.

In addition, tumors exposed to effective targeted therapies develop, sooner or later, acquired resistance and it can be hypothesized that resistance to gene-targeted agents also comes as a

consequence of the radical changes in the underlying patterns of gene expression that accompany the epithelial-mesenchymal cell transitions in cancer cells when their surrounding environments become hypoxic.

It should additionally be noted that areas of further exploration are focusing on the inhibition of the complex DNA repair machinery and, more specifically, on homologous recombination and end joining mechanisms to repair double strand breaks which arise from ionizing radiation or x-rays, free radicals and chemicals including cytotoxics.

In the near future, we will focus much more on the wide range of metabolic and oxidative vulnerabilities that arise as consequences of the uncontrolled growth and proliferation capacities of cancer cells.

Only the definition of homogeneous subgroups of tumors with the same genetic and metabolic characteristics and the search for individualized approaches could represent the way to improve survival expectancy for these patients.

Financial \& competing interests disclosure

The authors have no relevant affiliations or financial involvement with any organization or entity with a financial interest in or financial conflict with the subject matter or materials discussed in the manuscript. This includes employment, consultancies, honoraria, stock ownership or options, expert testimony, grants or patents received or pending, or royalties.

No writing assistance was utilized in the production of this manuscript.

\section{References}

Papers of special note have been highlighted as:

- of interest; $\bullet$ • of considerable interest

1 Siegel R, Naishadham D, Jemal A. Cancer statistics, 2012. CA Cancer J. Clin. 62, 102-9 (2012).

2 Howlader N, Noone AM, Krapcho M et al. Seer Cancer Statistics Review, 197-528. National Cancer Institute, MD, USA (2011).

3 Govindan R, Page N, Morgensztern D et al. Changing epidemiology of small-cell lung cancer in the United States over the last 30 years: analysis of the surveillance, epidemiologic, and end results database. J. Clin. Oncol. 24(28), 453-944 (2006).

4 Chemotherapy in non-small cell lung cancer: a meta-analysis using updated data on individual patients from 52 randomised clinical trials. Non-small Cell Lung Cancer Collaborative Group. Br. Med. J. 311, 899 (1995).
- Establishes the role of platinum-based chemotherapy doublets as the backbone of treatment for non-small-cell lung cancer (NSCLC).

5 NSCLC Meta-Analyses Collaborative Group. Chemotherapy in addition to supportive care improves survival in advanced non-small-cell lung cancer: a systematic review and meta-analysis of individual patient data from 16 randomized controlled trials. J. Clin. Oncol. 26(28), 4617 (2008).

6 Ardizzoni A, Boni L, Tiseo M et al. Cisplatin-versus carboplatin-based chemotherapy in first-line treatment of advanced non-small-cell lung cancer: an individual patient data meta-analysis. J. Natl Cancer Inst. 99(11), 847-857 (2007).

7 Schiller J, Harrington D, Belani C et al. Comparison of four chemotherapy regimens for advanced non-small cell lung cancer. N. Engl. J. Med. 346, 92-98 (2002).

8 Scagliotti G, De Marinis F, Rinaldi M et al. Phase III randomized trial comparing three platinum-based doublets in advanced non-small-cell lung cancer. J. Clin. Oncol. 20, 4285-4291 (2002).

9 Fossella F, Pereira J, von Pawel J et al. Randomized, multinational, Phase III study of docetaxel plus platinum combinations versus vinorelbine plus cisplatin for advanced non-small cell lung cancer: the TAX 326 study group. J. Clin. Oncol. 21, 3016-3024 (2003).

10 Delbaldo C, Michiels S, Syz N et al. Benefits of adding a drug to a single-agent or a 2-agent chemotherapy regimen in advanced nonsmall-cell lung cancer: a meta-analysis. JAMA 292(4), 470-484 (2004).

11 Scagliotti GV, Parikh P, von Pawel J et al. Phase III study comparing cisplatin plus 
gemcitabine with cisplatin plus pemetrexed in chemotherapy-naive patients with advancedstage non-small-cell lung cancer. J. Clin. Oncol. 26, 354-361 (2008).

-• Highlights the improved efficacy of pemetrexed-containing regimens in nonsquamous NSCLCs.

12 Scagliotti G, Hanna N, Fossella F et al. The differential efficacy of pemetrexed according to NSCLC histology: a review of two Phase III studies. Oncologist 14, 253-263 (2009).

13 Ciuleanu T, Brodowicz T, Zielinski C et al. Maintenance pemetrexed plus best supportive care versus placebo plus best supportive care for nonsmallcell lung cancer: a randomised, double-blind, Phase 3 study. Lancet 374(9699), 1432-1440 (2009).

14 Paz-Ares L, De Marinis F, Dediu M et al. Maintenance therapy with pemetrexed plus best supportive care versus placebo plus best supportive care after induction therapy with pemetrexed plus cisplatin for advanced non-squamous non-small-cell lung cancer (PARAMOUNT): a double-blind, Phase 3, randomised controlled trial. Lancet Oncol. 13, 247-255 (2012).

15 Paz-Ares L, De Marinis F, Dediu M et al. PARAMOUNT: final overall survival (OS) results of the Phase III study of maintenance pemetrexed (pem) plus best supportive care (BSC) versus placebo (plb) plus BSC immediately following induction treatment with pem plus cisplatin (cis) for advanced nonsquamous (NS) non-small cell lung cancer (NSCLC). J. Clin. Oncol. 30 (Suppl.), Abstract LBA7507 (2012).

16 Ceppi P, Volante M, Saviozzi S et al. Squamous cell carcinoma of the lung compared with other histotypes shows higher messenger RNA and protein levels for thymidylate synthase. Cancer 107, 1589-1596 (2006).

17 Kelly K, Crowley J, Bunn PA et al. Randomized Phase III trial of paclitaxel plus carboplatin versus vinorelbine plus cisplatin in the treatment of patients with advanced non-small-cell lung cancer: a Southwest Oncology Group Trial. J. Clin. Oncol. 19(13), 3210-3218 (2001).

18 Sandler A, Gray R, Perry MC et al. Paclitaxel-carboplatin alone or with bevacizumab for non-small-cell lung cancer. N. Engl. J. Med. 355, 254-260 (2006).

- First evidence of improved overall survival in advanced nonsquamous NSCLC patients treated with platinum-based chemotherapy and bevacizumab.
19 Cohen MH, Gootenberg J, Keegan P et al. FDA drug approval summary: bevacizumab (avastin) plus carboplatin and paclitaxel as first-line treatment of advanced/metastatic recurrent nonsquamous non-small cell lung cancer. Oncologist 12, 713-718 (2007).

20 Reck M, von Pawel J, Zatloukal P et al. Phase III trial of cisplatin plus gemcitabine with either placebo or bevacizumab as first-line therapy for nonsquamous non-small-cell lung cancer: AVAil. J. Clin. Oncol. 27, 1227-1234 (2009).

- Confirmation of improved survival outcomes for advanced nonsquamous NSCLC patients treated with bevacizumab in association to standard chemotherapy.

21 Reck M, J Pawel, Zatloukal P et al. Overall survival with cisplatin-gemcitabine and bevacizumab or placebo as first-line therapy for nonsquamous non-small-cell lung cancer: results from a randomised Phase III trial (AVAiL). Ann. Oncol. 21, 1804-1819 (2010).

22 Botrel T, Clark O, Clark L et al. Efficacy of bevacizumab (bev) plus chemotherapy (CT) compared with CT alone in previously untreated locally advanced or metastatic non-small cell lung cancer (NSCLC): systematic review and meta-analysis. Lung Cancer 74, 89-97 (2011).

23 Crinò L, Dansin E, Garrido P et al. Safety and efficacy of first-line bevacizumab-based therapy in advanced non-squamous non-smallcell lung cancer (SAiL, MO19390): a Phase 4 study. Lancet Oncol. 11, 733-740 (2010).

24 Socinski MA, Langer CJ, Huang JE et al. Safety of bevacizumab in patients with non-small-cell lung cancer and brain metastases. J. Clin. Oncol. 27, 525-561 (2009).

25 Besse B, Lasserre SF, Compton P et al. Bevacizumab safety in patients with central nervous system metastases. Clin. Cancer Res. 16, 269-278 (2010).

26 F Hoffmann-La Roche Ltd. Avastin (bevacizumab) summary of product characteristics 2009.

www.emea.europa.eu

27 Patel J, Hensing T, Rademaker A et al. Phase II study of pemetrexed and carboplatin plus bevacizumab with maintenance pemetrexed and bevacizumab as first-line therapy for nonsquamous non-small-cell lung cancer. J. Clin. Oncol. 27(20), 3284-3289 (2009).

28 Patel J, Bonomi P, Socinski $\mathrm{M}$ et al. Treatment rationale and study design for the pointbreak study: a randomized, open-label Phase III study of pemetrexed/carboplatin/ bevacizumab followed by maintenance pemetrexed/bevacizumab versus paclitaxel/ carboplatin/bevacizumab followed by maintenance bevacizumab in patients with stage IIIb or IV nonsquamous non-small-cell lung cancer. Clin. Lung Cancer 10(4), 252-256 (2009).

29 Patel J, Socinski MA, Garon EB et al. A randomized, open-label, Phase 3 , superiority study of pemetrexed (pem)+carboplatin (Cb)+bevacizumab (B) followed by maintenance Pem $+B$ versus paclitaxel $(\mathrm{Pac})+\mathrm{Cb}+\mathrm{B}$ followed by maintenance $\mathrm{B}$ in patients (pts) with stage IIIB or IV nonsquamous non-small cell lung cancer (NS-NSCLC). J. Thorac. Oncol. 7(9 Suppl. 4), S336 (2012).

30 Barlesi F, de Castro J, Dvornichenko V et al. Final efficacy outcomes for patients (pts) with advanced non-squamous non-small cell lung cancer (nsNSCLC) randomised to continuation maintenance (mtc) with bevacizumab (bev) or bev+pemetrexed (pem) after first-line (1L) bev-cisplatin (cis)-pem treatment (Tx). Eur. J. Cancer 47(Suppl. 2), 16 (2011).

31 Salomon DS, Brandt R, Ciardiello F et al. Epidermal growth factor-related peptides and their receptors in human malignancies. Crit. Rev. Oncol. Hematol. 9, 183-232 (1995).

32 Giaccone G, Herbst RS, Manegold C et al. Gefitinib in combination with gemcitabine and cisplatin in advanced non small-cell lung cancer: a Phase III trial - INTACT 1. J. Clin. Oncol. 22(5), 777-784 (2004).

33 Herbst RS, Giaccone G, Schiller JH et al. Gefitinib in combination with paclitaxel and carboplatin in advanced non small-cell lung cancer: a Phase III trial - INTACT 2. J. Clin. Oncol. 22(5), 785-794 (2004).

34 Gatzemeier U, Pluzanska A, Szczesna A et al. Phase III study of erlotinib in combination with cisplatin and gemcitabine in advanced non-small-cell lung cancer: the Tarceva lung cancer investigation trial. J. Clin. Oncol. 25(12), 1545-1552 (2007).

35 Herbst RS, Prager D, Hermann R; On behalf of the TRIBUTE Investigator Group et al. TRIBUTE: a Phase III trial of erlotinib hydrochloride (OSI-774) combined with carboplatin and paclitaxel chemotherapy in advanced non-small-cell lung cancer. J. Clin. Oncol. 23(25), 589-629 (2005).

36 Miller VA, Kris MG, Shah N et al. Bronchioloalveolar pathologic subtype and smoking history predict sensitivity to gefitinib in advanced non-small-cell lung cancer. J. Clin. Oncol. 22, 110-139 (2004).

37 Shah NT, Kris MG, Pao W et al. Practical management of patients with non-small-cell lung cancer treated with gefitinib. J. Clin. Oncol. 23, 165-174 (2005). 
38 Thatcher N, Chang A, Parikh P et al. Gefitinib plus best supportive care in previously treated patients with refractory advanced non-smallcell lung cancer: results from a randomised, placebo-controlled, multicentre study (Iressa Survival Evaluation in Lung cancer). Lancet 366, 1527-1537 (2005).

39 Kim ES, Hirsh V, Mok T et al. Gefitinib versus docetaxel in previously treated non-small-cell lung cancer (INTEREST): a randomised Phase III trial. Lancet 372, 1809-1818 (2008).

40 Lynch TJ, Bell DW, Sordella R et al. Activating mutations in the epidermal growth factor receptor underlying responsiveness of non-small-cell lung cancer to gefitinib. N. Engl. J. Med. 350, 2129-2139 (2004).

41 Paez JG, Jänne PA, Lee JC et al. EGFR mutations in lung cancer: correlation with clinical response to gefitinib therapy. Science 304, 1497-1500 (2004).

42 Pao W, Miller V, Zakowski M et al. EGF receptor gene mutations are common in lung cancers from 'never smokers' and are associated with sensitivity of tumors to gefitinib and erlotinib. Proc. Natl Acad. Sci. USA. 101, 1330-1611 (2004).

43 Shigematsu H, Lin L, Takahashi T et al. Clinical and biological features associated with epidermal growth factor receptor gene mutations in lung cancers. J. Natl Cancer. Inst. 97, 339-346 (2005).

44 Mok TS, Wu YL, Thongprasert S et al. Gefitinib or carboplatin-paclitaxel in pulmonary adenocarcinoma. N. Engl. J. Med. 361, 947-957 (2009).

- First evidence of efficacy of an EGF receptor-tyrosine kinase inhibitors as front-line treatment for patients with advanced NSCLC.

45 Lee JS, Park K, Kim SW et al. A randomized Phase III study of gefitinib (IRESSA) versus standard chemotherapy (gemcitabine plus cisplatin) as a first-line treatment for never-smokers with advanced or metastatic adenocarcinoma of the lung. Presented at: The 13th World Conference on Lung Cancer 2009. San Francisco, CA, USA, 31 July-4 August 2009 (Abstract PRS.4).

46 Mitsudomi T, Morita S, Yatabe Y et al. Gefitinib versus cisplatin plus docetaxel in patients with non-small-cell lung cancer harbouring mutations of the epidermal growth factor receptor (WJTOG3405): an open label, randomised Phase 3 trial. Lancet Oncol. 11, 121-128 (2010).

47 Maemondo M, Inoue A, Kobayashi K et al. Gefitinib or chemotherapy for non-small-cell lung cancer with mutated EGFR. N. Engl. J. Med. 362, 2380-2388 (2010).

48 Zhou C, Wu Y-L, Chen G et al. Erlotinib versus chemotherapy as first-line treatment for patients with advanced $E G F R$ mutationpositive non-small-cell lung cancer (OPTIMAL, CTONG-0802): a multicentre, open-label, randomised, Phase 3 study. Lancet Oncol. 12, 735-742 (2011).

49 Rosell R, Carcereny E, Gervais R et al. Erlotinib versus standard chemotherapy as first-line treatment for European patients with advanced EGFR mutation-positive non-smallcell lung cancer (EURTAC): a multicentre, open-label, randomised Phase 3 trial. Lancet Oncol. 13(3), 239-246 (2012).

- Highlights the superiority of erlotinib compared with standard platinum-based chemotherapy in front-line setting for advanced EGFR mutated NSCLCs.

50 Yang $\mathrm{CH}$, Fukuoka M, Mok TS et al. Final overall survival (OS) results from a Phase III: randomised, open-label, first-line study of gefitinib $(G) v$ carboplatin/paclitaxel $(C / P)$ in clinically selected patients with advanced non-small cell lung cancer (NSCLC) in Asia (IPASS). Ann. Oncol. 21(Suppl. 8), viii1-viii12 (2010) (Abstract LBA2).

51 Mok T, Wu YL, Yu CJ et al. Randomized, placebo-controlled, Phase II study of sequential erlotinib and chemotherapy as first-line treatment for advanced non-small-cell lung cancer. J. Clin. Oncol. 27, 5080-5087 (2009).

52 Mok T, Wu YL, Thongprasert $S$ et al. A randomized placebo-controlled Phase III study of intercalated erlotinib with gemcitabine/platinum in first-line advanced non-small cell lung cancer (NSCLC): FASTACT-II. J. Clin. Oncol. 30 (Suppl.), Abstract 7519 (2012).

53 Costa DB. To re-treat or not with gefitinib/erlotinib: this is the question for tyrosine kinase inhibitor-responsive lung cancers that progress. Lung Cancer 57, 251-252 (2007).

54 Yokouchi H, Yamazaki K, Kinoshita I et al. Clinical benefit of readministration of gefitinib for initial gefitinib-responders with non-small cell lung cancer. BMC Cancer 7, 51 (2007).

55 Tomizawa Y, Fujita Y, Tamura A et al. Effect of gefitinib re-challenge to initial gefitinib responder with non-small cell lung cancer followed by chemotherapy. Lung Cancer 68, 269-272 (2010).

56 Oh IJ, Ban HJ, Kim KS et al. Retreatment of gefitinib in patients with non-small-cell lung cancer who previously controlled to gefitinib: a single-arm, open-label, Phase II study. Lung Cancer 77, 121-127 (2012).

57 Koizumi T, Agatsuma T, Ikegami K et al. Prospective study of gefitinib readministration after chemotherapy in patients with advanced non-small-cell lung cancer who previously responded to gefitinib. Clin. Lung Cancer 13(6), 458-463 (2012).

58 Kobayashi S, Ji H, Yuza Y et al. An alternative inhibitor overcomes resistance caused by a mutation of the epidermal growth factor receptor. Cancer Res. 65, 7096-7101 (2005).

59 Oxnard GR, Arcila ME, Sima CS et al. Acquired resistance to EGFR tyrosine kinase inhibitors in EGFR-mutant lung cancer: distinct natural history of patients with tumors harboring the T790M mutation. Clin. Cancer Res. 17, 1616-1622 (2011).

60 Miller VA, Hirsh V, Cadranel J et al. Afatinib versus placebo for patients with advanced, metastatic non-small-cell lung cancer after failure of erlotinib, gefi tinib, or both, and one or two lines of chemotherapy (LUX-Lung 1): a Phase 2b/3 randomised trial. Lancet Oncol. 13, 528-538 (2012).

61 Yang J, Shih JY, Su WC et al. Afatinib for patients with lung adenocarcinoma and epidermal growth factor receptor mutations (LUX-Lung 2): a Phase 2 trial. Lancet Oncol. 13, 539-548 (2012).

62 Yang JC, Schuler MH, Yamamoto N et al. LUX-Lung 3: a randomized, open-label, Phase III study of afatinib versus pemetrexed and cisplatin as first-line treatment for patients with advanced adenocarcinoma of the lung harboring EGFR-activating mutations. J. Clin. Oncol. 30(Suppl.), Abstract LBA7500 (2012).

-• First evidence of survival benefit with afatinib as first-line treatment for lung adenocarcinoma harboring EGF receptor-activating mutations.

63 Wu YL, Zhou C, Hu CP et al. LUX-Lung 6: a randomized, open-label, Phase III study of afatinib (A) versus gemcitabine/cisplatin (GC) as first-line treatment for Asian patients (pts) with $E G F R$ mutation-positive (EGFR $\mathrm{M}^{+}$) advanced adenocarcinoma of the lung. J. Clin. Oncol. 31(Suppl.) Abstract 8016 (2013).

64 LUX-Lung 7: A Phase IIb Trial of Afatinib(BIBW2992) Versus Gefitinib for the Treatment of 1st Line EGFR Mutation Positive Adenocarcinoma of the Lung. http://clinicaltrials.gov/ct2/show/ NCT01466660

65 Ramalingam SS, Blackhall F, Krzakowski M et al. Randomized Phase II study of 
dacomitinib (pf-00299804), an irreversible panhuman epidermal growth factor receptor inhibitor, versus erlotinib in patients with advanced non-small-cell lung cancer. J. Clin. Oncol. 30(27), 3337-3344 (2012).

66 ARCHER 1009: A Study Of Dacomitinib (PF-00299804) Vs. Erlotinib In The Treatment Of Advanced Non-Small Cell Lung Cancer. http://clinicaltrials.gov/ct2/show/ NCT01360554

67 Ciardiello F, Tortora G. A novel approach in the treatment of cancer: targeting the epidermal growth factor receptor. Clin. Cancer Res. 7, 2958-2970 (2001).

68 Grunwald V, Hidalgo M. Developing inhibitors of the epidermal growth factor receptor for cancer treatment. J. Nat. Cancer Inst. 95, 8516-8517 (2003).

69 Pirker R, Pereira JR, Szczesna A et al. Cetuximab plus chemotherapy in patients with advanced non-small cell lung cancer (FLEX): an open-label randomised Phase III trial. Lancet 373, 1525-1531 (2009).

70 Lynch TJ, Patel T, Dreisbach L et al. Cetuximab and first-line taxane/carboplatin chemotherapy in advanced non-small-cell lung cancer: results of the randomized multicenter Phase III trial BMS099. J. Clin. Oncol. 28, 911-917 (2010).

71 Ibrahim EM, Abouelkhair KM, Al-Masri OA et al. Cetuximab-based therapy is effective in chemotherapy-naïve patients with advanced and metastatic non-small-cell lung cancer: a meta-analysis of randomized controlled trials. Lung 189(3), 193-198 (2011).

72 Kimura H, Sakai K, Arao T et al. Antibodydependent cellular cytotoxicity of cetuximab against tumor cells with wild-type or mutant epidermal growth factor receptor. Cancer Sci. 98, 1275-1280 (2007).

73 Matar P, Rojo F, Cassia R et al. Combined epidermal growth factor receptor targeting with the tyrosine kinase inhibitor gefitinib (ZD1839) and the monoclonal antibody cetuximab (IMC-C225): superiority over single-agent receptor targeting. Clin. Cancer Res. 10, 6487-6501 (2004).

74 Pirker R, Pereira JR, von Pawel J et al. EGFR expression as a predictor of survival for first-line chemotherapy plus cetuximab in patients with advanced non-small-cell lung cancer: analysis of data from the Phase 3 FLEX study. Lancet Oncol. 13, 33-42 (2012).

- Describes the EGF receptor expression level as predictive biomarker for response to cetuximab in advanced NSCLCs.

75 Dienstmann R, Felip E. Necitumumab in the treatment of advanced non-small cell lung cancer: translation from preclinical to clinical development. Expert Opin. Biol. Ther. 11(9), 1223-1231 (2011).

76 First-line Treatment of Patients With Stage IV Nonsquamous Non-Small Cell Lung Cancer With Necitumumab (IMC-11F8) and Pemetrexed-Cisplatin (INSPIRE). http://clinicaltrials.gov/show/NCT00982111

77 First-line Treatment of Participants With Stage IV Squamous Non-Small Cell Lung Cancer With Necitumumab and Gemcitabine-Cisplatin (SQUIRE). http://clinicaltrials.gov/show/NCT00981058

78 Soda M, Choi YL, Enomoto M et al. Transforming EML4-ALK fusion gene in non-small-cell lung cancer. Nature 448, 561-566 (2007).

79 Koivunen JP, Mermel C, Zejnullahu K et al. $E M L 4-A L K$ fusion gene and efficacy of an ALK kinase inhibitor in lung cancer. Clin. Cancer Res. 14, 42758-3 (2008).

80 Wong DW, Leung EL, So KK et al. The $E M L 4-A L K$ fusion gene is involved in various histologic types of lung cancers from nonsmokers with wild-type EGFR and KRAS. Cancer 115, 1723-1733 (2009).

81 Shaw AT, Yeap BY, Mino-Kenudson M et al. Clinical features and outcome of patients with non-small-cell lung cancer who harbor EML4-ALK. J. Clin. Oncol. 27, 4247-4253 (2009).

82 Inamura K, Takeuchi K, Togashi Y et al. EML4- $A L K$ lung cancers are characterized by rare other mutations, a TTF-1 cell lineage, an acinar histology, and young onset. Mod. Pathol. 22, 508-515 (2009).

83 McDermott U, Iafrate AJ, Gray NS et al. Genomic alterations of anaplastic lymphoma kinase may sensitize tumors to anaplastic lymphoma kinase inhibitors. Cancer Res. 68 , 3389-3395 (2009).

84 Zou HY, Li Q, Lee JH et al. An orally available small-molecule inhibitor of c-Met, PF-2341066, exhibits cytoreductive antitumor efficacy through antiproliferative and antiangiogenic mechanisms. Cancer Res. 67(9), 4408-4017 (2007).

85 Kwak EL, Camidge DR, Clark J et al. Clinical activity observed in a Phase 1 dose-escalation trial of an oral c-met and ALK inhibitor, PF-02341066. J. Clin. Oncol. 27(15 Suppl.), 3509 (2009).

86 Kwak EL, Bang YJ, Camidge DR et al. Anaplastic lymphoma kinase inhibition in non-small-cell lung cancer. $N$. Engl. J. Med. 363(18), 16937-03 (2010).

-• Underlines the potent activity of crizotinib in the majority of ALK-positive NSCLC patients.
87 Camidge DR, Bang Y, Kwak EL et al. Progression-free survival (PFS) from a Phase I study of crizotinib (PF-02341066) in patients with ALK-positive non-small-cell lung cancer (NSCLC). J. Clin. Oncol. 29(Suppl.), Abstract 2501 (2011).

88 Crinò L, Kim D-W, Riely G et al. Initial Phase II results with crizotinib in advanced ALK-positive non-small cell lung cancer (NSCLC): PROFILE 1005. J. Clin. Oncol. 29(Suppl.), Abstract 7514 (2011).

89 US FDA. www.fda.gov

90 An Investigational Drug, PF-02341066 Is Being Studied Versus Standard Of Care In Patients With Advanced Non-Small Cell Lung Cancer With A Specific Gene Profile Involving The Anaplastic Lymphoma Kinase $(A L K)$ Gene.

http://clinicaltrials.gov/show/NCT00932893

91 A Clinical Trial Testing The Efficacy Of Crizotinib Versus Standard Chemotherapy Pemetrexed Plus Cisplatin Or Carboplatin In Patients With ALK Positive Non Squamous Cancer Of The Lung (PROFILE 1014). http://clinicaltrials.gov/show/NCT01154140

92 Shaw AT, Kim DW, Nakagawa K et al. Phase III study of crizotinib versus pemetrexed or docetaxel chemotherapy in patients with advanced ALK-positive non-small cell lung cancer (NSCLC) (PROFILE 1007). Ann. Oncol. 23(Suppl. 9), Astract LBA1_PR (2012).

93 Shaw AT, Varghese AM, Solomon BJ et al. Pemetrexed-based chemotherapy in patients with advanced, ALK-positive non-small cell lung cancer. Ann. Oncol. 24(1), 59-66 (2013).

94 A Study Of Crizotinib Versus Chemotherapy In Previously Untreated ALK Positive East Asian Non-Small Cell Lung Cancer Patients. http://clinicaltrials.gov/ct2/show/ NCT01639001

95 Bergethon K, Shaw AT, Ou SHI et al. ROS1 rearrangements define a unique molecular class of lung cancers. J. Clin. Oncol. 30, 863-870 (2012).

96 Takeuchi K, Soda M, Togashi Y et al. RET, ROS1 and ALK fusions in lung cancer. Nat. Med. 18(3), 378-381 (2012).

97 Shaw AT, Camidge DR, Engelman JA et al. Clinical activity of crizotinib in advanced non-small cell lung cancer (NSCLC) harboring ROS1 gene rearrangement. J. Clin. Oncol. 30 (Suppl.), Abstract 7508 (2012).

- First evidence of marked anti-tumor activity of crizotinib in NSCLCs harboring ROS1 chromosomal rearrangements. 